\title{
Supply Chain Management Practices in Printing Industry
}

\author{
G.V.R.K. Acharyulu \\ University of Hyderabad, Hyderabad 500046, India \\ Email: acharyulu_gvrk@yahoo.com,gvrkams@uohyd.ernet.in
}

\begin{abstract}
The Indian Printing Industry is well established and presently growing at $12 \%$ per annum. According to NPES/PRIMIR (2006) report, there are more than 8000 daily newspapers published in India, besides a large number of weekly and fortnightly periodicals published in all Indian languages. The Indian Printing Industry today comprises more than $\mathbf{2 5 0 , 0 0 0}$ big, small and medium printers. Business models and technology strategies of SCM need to be monitored very closely to adopt changes in the print supply chain environment. This paper is to examine supply chain management practices, issues, role of information technology in printing industry. A convenient sample of 70 companies/individuals from operations department was selected with a questionnaire for conducting survey. This sample ranges across printing companies, publishers, material suppliers like paper, ink, etc., from the population of around $\mathbf{2 5 0 0}$ companies in around Hyderabad. In addition to data collection through a questionnaire, interactions carried out with material suppliers and the customers or the print-buyers to find out how they operate, and seek their opinion on the practices being followed and to know their expectations in efficiently managing the operations of print supply chain. The paper is to make a small attempt to understand the advantage of adopting information technology solutions in printing industry for a seamless information flow across entire value chain, so as to operate efficiently by reducing cost.
\end{abstract}

Keywords: print supply chain, information technology, logistics, suppliers, inventory

\section{INTRODUCTION}

The Indian Printing Industry is well established and presently growing at $12 \%$ per annum. According to NPES/PRIMIR (2006) report, India is the world's fastest growing printing market with a $73 \%$ rate of growth from 2006-2011. India's printing market is about $\$ 12.1$ billion and is forecast to grow to US \$ 20.9 billion in a year's time. There are more than 8000 daily newspapers published in India, besides a large number of weekly and fortnightly periodicals published in all Indian languages. The Indian Printing Industry today comprises more than 250,000 big, small and medium printers according to The All India Printing Ink Manufacturers Association (2002).

India has one of the fastest growing print industries in the world. Indian books, journals and printed products are exported to more than 120 countries. More than 1, 30,000 types of printing presses, more than a crore of people are employed in this industry. Indian printing industry has gone through a revolutionary transformation in the last 15 years because of liberalization of economy and privatization of the industries. Newspaper, Periodicals and Magazines publish- ing houses are sanctioned 26 per cent Foreign Direct Investment (FDI) and government is assessing the request for uplift in FDI from 26 to 49 per cent. Printing industry encompasses several fields of the economy and generates a wide range of products which affects our day to day life. Printing industries all over the world are applying lean manufacturing in order to reduce cost, make use of available limited resources, improve quality and respond quickly to the demand of the customer.

Supply chain management is defined as the coordination or integration (sharing information and working together) of key business processes among trading partners to improve the flow of goods, services and information, while reducing overall supply chain costs and maintaining the required levels of quality and customer service (Christopher 2004, Simchi-Levi et al. 2007). Supply chain management practices involve a set of activities undertaken within an organization and integrated with its trading partners (suppliers and customers) to promote effective management of a supply chain (Koh et al. 2007, Li et al. 2005 and 2006, and Frohlich and Westbrook 2001).

As Spens \& Wisner (2009) note the practice of Supply chain management is receiving a growing amount of interest from practitioners as well as academia, and many efforts to explain and describe the essence of SCM exist in the literature. The literature has supported that SCM practices are portrayed from different perspectives with a common aim of improving organizational performance (Chong et al. 2011).

SCM practices are defined as the set of activities undertaken by an organization to promote effective management of its supply chain; as the approaches applied in integration, managing and coordination of supply, demand and relationships in order to satisfy clients in effective way; as tangible activities/technologies that have a relevant role in the collaboration of a focal firm with its suppliers and/or clients; and as the approach to involve suppliers in decision making, encouraging information, sharing and looking for new ways to integrate upstream activities (Valmohammadi, 2013).

\section{OBJECTIVES}

The objectives of the study are:

- To examine the practices being followed in printing supply chain,

- To understand the problems in the print supply chain and role of Information Technology.

\section{METHODOLOGY}

The study is explorative in nature and aims to identify supply chain management practices in printing 
industry. A convenient sample of 70 individuals from Operations department of printing companies was approached with a questionnaire to collect the primary data. This sample ranges across 18 printing production executives, 25 publishers, 27 material suppliers like paper, ink, etc., from the population of around 2500 companies (All India Federation of Master Printers AIFMP, Workforce Survey, 2001) in around Hyderabad. The publishers include books, magazines, newspapers and graphic designers.

The questionnaire items consist of 6 point rating scale: 1- Very Unimportant 2- Unimportant 3- Somewhat Unimportant 4- Somewhat important 5- Important 6- Very important focusing on communication, relationship and management support as a part of print supply chain practices.

In addition to data collection through a questionnaire, interactions carried out with material suppliers and the customers or the print-buyers to find out how they operate, and seek their opinion on the practices being followed and to know what their expectations are in the efficient and effective operation of print industry supply chain.. Data analysis entailed the use of descriptive methods to provide exploratory insights into the nature of Supply chain management practices in the printing industry. The data was analyzed using descriptive statistics and Chi-Square test to test the significant relationship between communication and other items

\section{PRINT SUPPLY CHAIN OPERATIONS}

\subsection{Procurement}

It's a common practice to forecast the demand based on the seasonality of some specific jobs like Calendars during August to January of every year, Annual Reports during May to September, etc. The forecasting process is based on past data and is generally not accurate, as there's no guarantee that the customer who got a Calendar printed last year comes again for the current year calendar. Newspaper and Magazine printing companies do have clear information of daily, weekly and monthly requirements of raw materials. The forecasting is done based on the circulation data of these publications.

Large Commercial Printers do stock necessary important raw material like paper and inks, so as to meet the customers' requirements on a regular basis, while maintaining buffer stocks for any emergency and have a very long-standing, strategic relationships with their suppliers. They do share their regular consumption information with the suppliers and work in a very transparent manner with the suppliers - dealers, distributors \& manufacturers.

Most of the small printing companies do not have any computer-based systems to manage their inventory and order processing. They depend on the distributors/dealers for their operational requirements. Many small printing companies do purchase raw materials on credit basis, so the preferred supplier is the one who extends credit facility for the payment. Once the credit facility gets exhausted, the small printer usually tries to source raw material through another dealer/distributor who extends credit facility.

The suppliers are under pressure to increase sales and also to withstand the competition, resort to lower prices and credit facility. Once the credit extended becomes unmanageable, facing severe crunch of cash flows, they insist on cash and carry for any further purchases from small printing companies.

\subsection{Vendor Managed Inventory (VMI)}

Few established raw-material suppliers like Kodak Polychrome and others are adopting Vendor Managed Inventory so as to ease the pressure on the printing companies. The printing companies no longer have to worry about ordering huge quantities and stocking them - lockingup scarce capital, transportation and storage space, etc.

VMI is getting popular with most players in the Industry and will become a standard practice soon for many items.

The printing companies can enjoy the just-in-time (JIT) inventory, with replenishments flowing-in at regular intervals, by opting for the suppliers who can work with them closely and offer vendor-managed inventory. It's like a win-win situation for both - the printers and the suppliers. The suppliers can have the advantage of signing-up long term contracts which brings in realistic information on how much to produce, stock. VMI also helps in pull-based SCM for the manufacturers of paper, plates, etc. who otherwise want to always push their stocks into the market through dealers.

\subsection{Logistics}

None of the commercial printers maintain a huge fleet of trucks either for transporting the inbound materials or for outbound finished goods. All the inbound logistics are usually taken care by 3PL providers, or by the manufacturer/supplier's own fleet of trucks. The large printing companies, newspaper companies maintain their paper god owns spread across different places near their manufacturing plant. A small fleet of trucks is deployed to transport the required paper to the manufacturing plant for fulfilling the daily orders. In case of direct imports, paper, plates, films, inks are shipped through sea-freight and then through the 3PL trucks from the ports to the respective customer.

Contained station is getting increasingly popular in import of major raw material like paper, plates, etc, enabling a multi-modal transport - goods are transported across more than one mode in an integrated and seamless manner from the points of origin to the points of destination using a combination of rail, road, canal and maritime transport.

Air Freight is used for items, which are not so heavy, and also for the items which are required on a very urgent basis. All the outbound logistics are again predominantly supported by 3PL - unorganized trucking companies, road transport companies like GATI, courier companies like Blue-Dart, FedEx. All these companies offer some kind of tracking system of the shipments. In case of FedEx, the transparency offered is quite high with high a degree of reliability of delivery in time. The following figure will illustrate the print supply chain operations. 


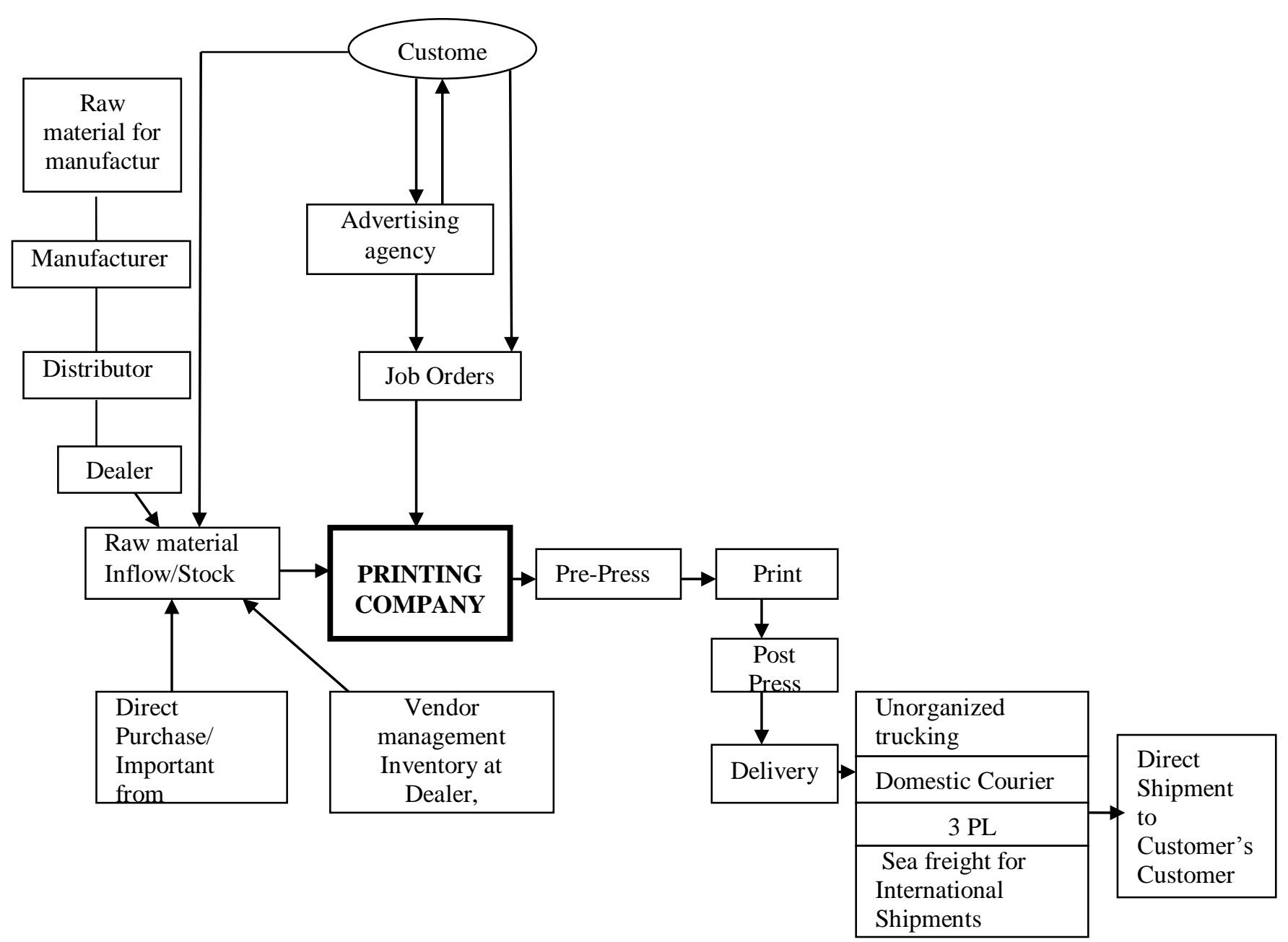

Figure 1 Supply Chain in Printing Industry

In the above figure, the customer procures paper from manufacturers, distributor, dealer, and supplier to printing company on job by job basis. The raw material consists of paper, films, inks, chemicals, binding \& packaging, and finshing material. Running a sustainable printing business requires a holistic approach, rather than a disjointed set of efforts. First, it includes ensuring that the actual product you are printing and the raw materials required to produce it are sourced. Second, the manufacturing process, which includes pre-press, printing and post-press. Third, the printer's operation itself, including the building, transportation. This industry includes companies such as suppliers, publishing houses, printing brokers, salespersons, print media, advertising agents, academic institutions, equipment vendors, and other service providers and manufacturers.

\section{PROBLEMS FROM THE CUSTOMER SIDE}

The major problem being faced by everyone: suppliers, manufacturing companies, and the customers in the industry are the unpredictable and unplanned orders flowing-in the lack of proper planning at each end is a major cause of concern for procuring and maintaining optimized inventory at printing manufacturing facility. For example a company likes Hutch who signs up with an ad agency O\&M for all their advertising and printing requirements. This contract is usually for a long period -anywhere from 2 to 5 years. Despite working with a partner on a long-term basis, Hutch is simply not in a position to give their requirements information in advance to O\&M. And O\&M in turn who gets the Hutch orders executed by a particular printer is not in a position to give any advance information about the impending order. When all of a sudden Hutch realizes that they want to come out with a major promotional offer, they simply call O\&M and give a very short turn-around time for the complete delivery of service.

This kind of uncertainty till the last moment puts pressure on the printers, to build extra inventory of raw materials, to build extra production capacity so as to meet the tough production deadlines. In case the project requires some specialty materials; one has to put frantic efforts in identifying and sourcing a particular raw material.

\subsection{Lack of Credible and Reliable Supply Channels}

Most of the small-time dealers, distributors go by their gut-feeling in maintaining stock levels in sufficient quantity to meet the demand from printers. Even though they go by the past data and general industry trends, the dependency on gut-feeling in taking major decisions like how much to order from the manufacturers of raw-materials, results piling-up of extra stocks and in some times very low-levels of stock which means loss of business, when there is an order from a 
printing company. Wood pulp constitutes major component in manufacturing of paper. Lot of other chemicals/add-on going up to 200 in no. are required to manufacture paper. Many Indian companies manufacturing Indian Art paper and Maplitho paper do source material from local market only. Some companies, who are producing high-quality paper, procure raw materials from outside from various other countries.

\subsection{Valuing Information for Enhancement of Supply Chain Management}

The value of strategic knowledge is determined by the organization's performance in the marketplace. As this performance is dependent on the overall business environment and must be measured over time, evaluating the "value" of knowledge or wisdom is very difficult. One can only assume that companies who "guess right" consistently have real knowledge and even wisdom embedded in them.

Valuing tactical information is somewhat easier, especially if we limit ourselves to a supply chain context. The metrics can be very straightforward. For example, how much inventory reduction is associated with a perfect forecast? Does information allow better delivery service, and if so, how much better? What costs will be reduced, and by how much, if information on demand is visible throughout the supply chain?

It is observed that higher level of shared information and communication with supply chain partners' lead to integration and greater responsiveness among the chain members. Several large companies spend up to $50 \%$ of their annual capital expenditure in IT systems. It is more for survival than competitive advantage that companies are investing heavily in IT systems. IT makes it possible to collect, store and communicate to others the large pool of information by giving us increasingly sophisticated analysis, modeling, and decision support capabilities. In fact, advances in communication and computerized decision support systems are making it possible to deal with the growing complexities of a supply chain, incorporating more and more people and more relevant factors in the decision making.

\section{THE INFORMATION TECHNOLOGY VIEW OF SUPPLY CHAIN}

Supply Chain Management is all about the use of information technology to endow computerized intelligence to an ever-growing network of raw material suppliers, factories, warehouses, distribution centers, delivery vehicles and point-of-sale. By means of these capabilities, each player in the supply chain conducts business with the latest and best information from everyone else. Product moves from point-of-origin to that of consumption is quickly as possible and at the smallest cost, as supply and demand fall into an evermore-perfect balance.

\subsection{Track \& Trace Systems in Trucking and Transportation \\ With the advent of new technologies like Telema- tics - Telecommunication and Information Technologies}

supported by advanced technologies like Geographic Information Systems, there is greater urgency among all the logistics providers to employ truck-tracking/tracing systems. This will greatly help them monitor the movement of the goods, and also optimize the transportation needs by dynamically change the route or suggest an alternate path to carry or pick-up any additional material enroute.

While package/shipment tracking systems are widely in use from a long time in the courier companies, the usage of vehicle tracking systems across a wide geographical area, gives greater control to manage the logistics effectively [5]

\subsection{Supply Chain Management Software}

Supply Chain Management has been greatly helped by the emergence of sophisticated and evolving software in the past decade. SCM software could be classified into supply chain transaction software - ERP the key one here - and supply chain planning or optimizer software offered by the companies like i2, PeopleSoft, etc.

\section{DATA ANALYSIS}

The responses reflect that only $26 \%$ of respondents consider the open lines of communication as very important, while $29 \%$ of the respondents considered it to be just important. 79 percent of the respondents felt that adequate resources are allotted to develop and support SCM practices. $71 \%$ of the companies are exchanging information through website / email with suppliers and customers. EDI system is not yet implemented and $19 \%$ of the companies are adopting ERP system. Most of the respondents (72\%) felt that trust worthy relationship with suppliers is important. Involvement of top and middle level management support is very essential for improving the supply chain. $76 \%$ respondents felt that improvements in communication, inbound and out-bound logistics is important. The analysis was shown in following Tables 1-6.

Table 1 How critical the open lines of communication and engaging in cross-function discussion with customers?

\begin{tabular}{|l|c|c|}
\hline Responses & Respondents & Percentage \\
\hline Very Unimportant (1) & 3 & 4 \\
\hline Unimportant (2) & 2 & 3 \\
\hline $\begin{array}{l}\text { Somewhat Unimportant } \\
(3)\end{array}$ & 10 & 14 \\
\hline Somewhat important (4) & 17 & 24 \\
\hline Important (5) & 20 & 29 \\
\hline Very important (6) & 18 & 26 \\
\hline \multicolumn{1}{|c|}{ Total } & 70 & 100 \\
\hline
\end{tabular}

Table 2 Does your company believe that adequate resources are allocated to developing and supporting SCM practice with you?

\begin{tabular}{|l|c|c|}
\hline Responses & $\begin{array}{c}\text { No. of } \\
\text { Respondents }\end{array}$ & Percentage \\
\hline Yes & 55 & 79 \\
\hline No & 5 & 7 \\
\hline Neither nor & 10 & 14 \\
\hline Total & 70 & 100 \\
\hline & & \\
\hline
\end{tabular}


Table 3 What type of system is presently being in exchanging information such as receiving order?

\begin{tabular}{|l|c|c|}
\hline \multicolumn{1}{|c|}{ Responses } & No. of Respondents & Percentage \\
\hline ERP & 13 & 19 \\
\hline Websitelemail & 50 & 71 \\
\hline EDI & 0 & 0 \\
\hline Other & 7 & 10 \\
\hline Total & 70 & 100 \\
\hline
\end{tabular}

Table 4 When asked on how important, developing a trustworthy relationship with suppliers

\begin{tabular}{|l|c|c|}
\hline \multicolumn{1}{|c|}{ Responses } & $\begin{array}{c}\text { No of } \\
\text { Respondents }\end{array}$ & Percentage \\
\hline Very Unimportant (1) & 2 & 3 \\
\hline Unimportant (2) & 3 & 4 \\
\hline Somewhat Unimportant (3) & 6 & 9 \\
\hline Somewhat important (4) & 8 & 11 \\
\hline Important (5) & 22 & 31 \\
\hline Very important (6) & 29 & 41 \\
\hline Total & 70 & 100 \\
\hline
\end{tabular}

Table 5 On the involvement of top and middle management and their commitment in improving supply chain practice

\begin{tabular}{|l|c|c|}
\hline \multicolumn{1}{|c|}{ Responses } & $\begin{array}{c}\text { No. of } \\
\text { Respondents }\end{array}$ & Percentage \\
\hline To no extent (1) & 0 & 0 \\
\hline To very little extent (2) & 0 & 0 \\
\hline To a little extent (3) & 1 & 1 \\
\hline To Some extent (4) & 7 & 10 \\
\hline To a great extent (5) & 28 & 40 \\
\hline Completely (6) & 34 & 49 \\
\hline Total & 70 & 100 \\
\hline
\end{tabular}

Table 6 When asked on how important is the improvements in communication, in-bound and out-bound logistics activity

\begin{tabular}{|l|c|c|}
\hline \multicolumn{1}{|c|}{ Responses } & $\begin{array}{c}\text { No. of } \\
\text { Respondents }\end{array}$ & Percentage \\
\hline Very Unimportant (1) & 2 & 3 \\
\hline Unimportant (2) & 1 & 1 \\
\hline Somewhat Unimportant (3) & 5 & 7 \\
\hline Somewhat important (4) & 9 & 13 \\
\hline Important (5) & 18 & 26 \\
\hline Very important (6) & 35 & 50 \\
\hline Total & 70 & 100 \\
\hline
\end{tabular}

In order to understand the how the importance of SCM practices were perceived among the respondents, the descriptive mean and Standard Deviations were analyzed in Table 7.

The data shows that there is statistically significant relationship between communication and relationship with suppliers, communication and cross function decision with customers, Type of system for communication Vs. Importance of communication in logistics. The Chi-Square test result was shown in the Table 8.

Respondents felt that the barriers and challenges in implementing SCM practice are: i). Difficult information sharing with suppliers/customers, ii). Lack of external support, iii). Lack of budget, iv). too costly to implement. Respondents also felt that for a most optimized supply chain one should integrate the following activities: i). Purchasing, ii). Manufacturing, iii). Logistics, iv). Demand Forecasting and v). Inventory Control.

Table 7 Descriptive - Mean and Standard Deviation Sample size (N = 70)

\begin{tabular}{|c|l|c|c|}
\hline S.No & \multicolumn{1}{|c|}{ Item } & $\begin{array}{c}\text { Standard } \\
\text { Deviation }\end{array}$ \\
\hline 1 & How critical the open lines of communication and engaging in cross-function discussion with customers? & 4.47 & 1.32 \\
\hline 2 & When asked on how important, developing a trustworthy relationship with suppliers & 4.88 & 1.31 \\
\hline 3 & $\begin{array}{l}\text { On the involvement of top and middle management and their commitment in improving supply chain } \\
\text { practice }\end{array}$ & 5.35 & 0.72 \\
\hline 4 & $\begin{array}{l}\text { When asked on how important are the improvements in communication, in-bound and out-bound logistics } \\
\text { activity }\end{array}$ & 5.07 & 1.23 \\
\hline
\end{tabular}

Table 8 Chi-Square Tests

\begin{tabular}{|c|l|c|c|c|}
\hline S.No & \multicolumn{1}{|c|}{ Relationship } & $\begin{array}{c}\text { Person Chi- } \\
\text { Square Value }\end{array}$ & $\begin{array}{c}\text { Degrees } \\
\text { of } \\
\text { Freedom }\end{array}$ & $\begin{array}{c}\text { Asymp.Significance } \\
\text { (2 sided) }\end{array}$ \\
\hline 1 & Communication Vs relationship with suppliers & 40.64 & 25 & $0.025^{*}$ \\
\hline 2 & Communication Vs. cross function decision with customers & 46.92 & 25 & $0.005^{*}$ \\
\hline 3 & Type of system for communication Vs. Importance of communication in logistics & 30.57 & 15 & $0.01^{*}$ \\
\hline
\end{tabular}

* Indicates significance at Alfa $=0.05$

Respondents felt that the barriers and challenges in implementing SCM practice are: i). Difficult information sharing with suppliers/customers, ii). Lack of external support, iii). Lack of budget, iv). too costly to implement. Respondents also felt that for a most optimized supply chain one should integrate the following activities: $i$ ). Purchasing, ii). Manufacturing, iii). Logistics, iv). Demand Forecasting and v). Inventory Control.

Print service providers can play a key role in helping customers achieve corporate goals by getting connected, both from the perspective of reducing customers' overall procurement costs and cycle times, as well as helping them manage just-in-time inventories. E-Business solutions foster collaboration and bring all parties involved in a project together, enabling more effective communications.

\section{FINDINGS}

In the current business environment, which is highly competitive and unpredictable, the printing industry has to find a way to strengthen its position as a vital link in the market.

Some of the problems identified are:

- Lack of accurate demand forecasting methods

- $\quad$ Lack of reliable supply channels

- Lack of long-term relationships among customers, printers and suppliers, except in few cases. 
- $\quad$ For some of the materials, which need to be imported, the tendency among the sound printers is to build huge inventory, to cut down transportation costs and also to avoid foreign currency fluctuation.

- $\quad$ No reliable logistics support. Many of the transportation requirements are met by unorganized trucking companies and for small quantities the courier companies are being used.

\section{LIMITATIONS OF THE STUDY}

The study present only a snapshot view of the SCM practices in printing industry in Hyderabad. As the sample is convenient, the analysis may not reflect full cross-sectional view of the industry. The study excludes the digital printing component in the printing supply chain. Further, as the printing industry is highly fragmented, concept of supply chain management is complex and involves a network of companies in the effort of producing and delivering a service.

\section{FUTURE RESEARCH DIRECTIONS}

This research opens the way for in-depth studies of concern identified supply chain management practices. Research may be carried out using specific cases to study these practices in large number of firms in detail. It may be worthwhile to investigate how these practices differ across firm size. Finally, research should also focus on establishing actual performance improvements in supply chain management leading to cost-savings and customer satisfaction. Many printers are shifting adopt web-to-print, a prepress process that allows a graphic designer or printer to work directly with their customers to efficiently edit the design and layout of a project. This new model is "distribute first, print later."

\section{CONCLUSION}

As Zailani et al. (2008) argue the sharing of information among firms in a supply chain reflects the importance of SCM. Also, development and improvement of IT infrastructures should be given high priority in the printing industry. Various SCM authors and scholars have emphasized on the important role of IT in the coordination of supply chain (Chatzoudes \& Chatzoglou, 2011). Business models and technology strategies of SCM need to be monitored very closely to adopt changes in the print supply chain environment.

India is becoming one of the major print producer and manufacturer of printed paper products for the world markets. The printing industry's quality standards have improved dramatically with immense production capacities. Today the progressive printers are equipped with the latest computer controlled printing machines and flow lines for binding, while the state of the art digital technologies are being used in pre-press. Leading printing companies have optimized the use of information technology in each and every area of the printing business. The growth of the printing industry will be driven by external factors such as liberalization, competition, rising capital cost and spiraling costs of reaching vast markets and by internal factors like streamlining processes, increasing visibility using ERP, IT and plain old communication among people.

The results of this paper indicate that operating policies, proper usage of information technology systems, strategic alliance, better communication across inbound and outbound activities of the supply chain, performance measures, supplier relationships are the most important SCM practices of printing industry. As the printing industry is highly fragmented, there is a need to integrate internal and external operations with the usage of information technology for a seamless information flow across entire value chain, so as to operate efficiently by reducing cost. Existing players are continuously evolving and encourage customers aggressively with their attractive value offers.

\section{REFERENCES}

Cost, F. (2005). The new medium of print: Material communication in the Internet age. Rochester, Graphic Arts Press, NY: Rochester Institute of Technology.

Chong, A. Y. L., Chan, F. T. S., Ooi, K. B., and Sim, J. J. (2011). Can Malaysian firms improve organizational/innovation performance via SCM? Industrial Management \& Data Systems, 111(3), pp. 410-431.

Chatzoudes, D., and Chatzoglou, P. (2011). The Impact of 360 Supply Chain Integration on Operational and Business Performance, Operations and Supply Chain Management, 4(2/3), pp.145-156.

Christopher, M. (1998). Logistics and Supply Chain Management, Pitman, London.

Frohlich, M. and Westbrook, R. (2001). Arcs of integration: An international study of supply chain strategies. Journal of Operations Management, 19(2), pp. 185200.

Koh, S., Demirbag M., Bayraktar, E., Tatoglu, E. and Zaim S. (2007). The impact of supply chain management practices on performance of SMEs Industrial Management \& Data Systems, 107(1), pp. 103 - 124.

Li, S., Ragu-Nathan, B., Ragu-Nathan, T., Rao, S. (2005).Development and validation of a measurement for studying supply chain management practices. Journal of Operations Management, 23(6), pp. 618641.

Li, S., Ragu-Nathan, B., Ragu-Nathan, T., Rao, S. (2006). The impact of supply chain management practices on competitive advantage and organizational performance Omega, 34(2), pp. 107-124.

Sahay, B.S., Ramneesh Mohan, (2003), Supply chain management practices in Indian industry, International Journal of Physical Distribution \& Logistics Management, 33(7), pp.582 - 606,

Sahay, B.S. (Ed.) (2001),Supply Chain Management for Global Competitiveness, Macmillan, New Delhi.

Simchi-Levi, D., Kaminsky, P. and Simchi-Levi, E. (2007). Designing and managing the supply chain, 3rd Ed., McGraw-Hill/Irwin, New York.

Spens, K., and Wisner, J. (2009). A Study of Supply Chain Management Practices in Finland and the United States, Operations and Supply Chain Management, 2(2), pp. 79-92. 
Valmohammadi, Ch. (2013). Investigating Supply Chain Management Practices in Iranian Manufacturing Organizations, Operations and Supply Chain Management, 6(1) pp. 36 - 42.
Zailani, S., Premkumar, R., and Fernando, Y. (2008). Factors Influencing the Effectiveness of Operational Information Sharing within Supply Chain Channels in Malaysia, Operations and Supply Chain Management, 1(2), pp. 85-10.

G.V.R.K.Acharyulu is Associate Professor in Operations and Supply Chain Management, Coordinator - MBA (Healthcare \& Hospital Management) at the School of Management Studies, University of Hyderabad. He is the visiting professor at School of Engineering and Technology, Asian Institute of Technology (AIT), Bangkok. He is currently the Vice President, ISDSI- Conferences \& Programs Indian Sub-continent. He has 14 years of teaching in management subjects like Operations and Quantitatives, Supply Chain Management, Information Systems, Healthcare Management, Theory of Constraints, Technology Management and 10 years of industry experience in Operations and Materials divisions. He has published 20 research papers in National and 10 in International Journals in the area of Operations, Supply Chain and Healthcare Management. He has presented various research papers at International Conferences held in USA, Australia, Singapore, Malaysia, Thailand and Dubai. He has published 9 books on "Research Methodology \& Statistical Tools, Marketing Research, Logistics and Supply Chain Management, Strategic Quality Management (edited) through Excel Publications, New Delhi and Pharmacy Administration, IKON publishers, New Delhi, Emerging Trends in Healthcare Management (edited) from Paramount publications, Supply Chain Management in Healthcare Industry, Lambert Publications, Germany. His current research areas include Quantitative Techniques, Operations Research, Operations and Supply Chain Management, Modeling and Healthcare Management. 